This item was submitted to Loughborough's Research Repository by the author.

Items in Figshare are protected by copyright, with all rights reserved, unless otherwise indicated.

\title{
Critical load profile estimation for sizing of battery storage system
}

PLEASE CITE THE PUBLISHED VERSION

\section{PUBLISHER}

(C) IEEE

\section{VERSION}

AM (Accepted Manuscript)

\section{PUBLISHER STATEMENT}

This work is made available according to the conditions of the Creative Commons Attribution-NonCommercialNoDerivatives 4.0 International (CC BY-NC-ND 4.0) licence. Full details of this licence are available at: https://creativecommons.org/licenses/by-nc-nd/4.0/

\section{LICENCE}

CC BY-NC-ND 4.0

\section{REPOSITORY RECORD}

Sharma, Desh D., Sri Niwas Singh, Bharat Singh Rajpurohit, and Francisco M. Gonzalez-Longatt. 2019. "Critical Load Profile Estimation for Sizing of Battery Storage System". figshare.

https://hdl.handle.net/2134/17688. 


\title{
Critical Load Profile Estimation for Sizing of Battery Storage System
}

\author{
Desh Deepak Sharma ${ }^{1}$, S.N.Singh ${ }^{1}$, B.S. Rajpurohit ${ }^{2}$, F.G. Longatt ${ }^{3}$, \\ ${ }^{1}$ Electrical Engineering Department, IIT Kanpur, India ddsharma@iitk.ac.in, snsingh@iitk.ac.in \\ ${ }^{2}$ School of Computing \& Electrical Engineering, IIT Mandi, India, bsr@iitmandi.ac.in \\ ${ }^{3}$ School of Electronic, Electrcial \& Systems Engg., Loughborough Univ. UK, F.Gonzalez-Longatt@lboro.ac.uk
}

\begin{abstract}
In this paper, a method to find the critical load profile for estimating the battery storage size is proposed. The critical load profile consists of broadest peak in annual historical load profile data and is assumed an outlier. The LOF (local outlier factor) approach is implemented in finding the outliers, which are ranked according to degree of anomalies. The discharge duration in critical load profile, with consideration of annual load growth, helps in deciding the expected size of battery energy storage system (BESS) for the year of interest. The BESS sized with this power and energy ratings is useful in daily time deferrals, load leveling and peak shaving applications.
\end{abstract}

Index Terms-Broadest peak, discharge intervals, critical load profile, local outlier factor

\section{Nomenclature}

$\begin{array}{ll}\Omega & \text { Load profile data } \\ C E N_{j} & \text { Centroid load profile of } j^{\text {th }} \text { cluster } \\ d C E N_{j}^{i} & \text { Demand in } C E N_{j} \text { at } i^{\text {th }} \text { time interval, MW } \\ C_{j} & \text { Set of load profile in } j^{\text {th }} \text { cluster } \\ C_{\text {peak }} & \text { Set of load profile in cluster of peak load } \\ C L P^{b} & \text { Critical load profile for base year } \\ C L P^{r} & \text { Critical load profile for year of interest } \\ n_{c} & \text { No. of clusters in load pattern data } \\ n_{l} & \text { No. of load profiles in } C_{\text {peak }} \\ T & \text { Total no. of time intervals in a day } \\ E_{\text {tot }} & \text { Daily total energy demand, MWh } \\ N_{d s c h} & \text { Daily no. of discharge intervals, hrs } \\ \delta_{d s c h} & \text { Discharge duration, hrs } \\ P_{\max } & \text { Maximum power demand, MW }\end{array}$

\section{INTRODUCTION}

With the advancement in the energy storage technologies, it is becoming feasible to store some amount of electricity for certain period of time. At the substation and feeder levels, the batteries can be installed for reducing the impact of intermittency of renewable power generation, peak load shaving and load leveling, voltage stabilization, reduced cold loads and load transfers, reactive power compensation, etc. If the batteries are located near to the load end, the distribution system reliability can be enhanced very effectively even with the variability associated with distributed energy sources, and

Authors acknowledge the financial support received from DSTUKIERI, New Delhi to carry out this research. DD Sharma also acknowledges the MJP Rohilkhand University, UP for providing leave for pursuing PhD at IIT Kanpur. electric vehicles. With employment of batteries, two-way power flow is possible in the system as and when required. The wind and solar energy generation can be stored to dispatch later during peak load demand which is less predictable [1-5].

In the load leveling applications in the distribution system, the batteries flatten the load demand at upstream grid on assumed time intervals. The battery capacity during discharging with varying electricity demand depends on pattern of the load at different time intervals that is to be covered by the BESS. Thus, there is a need to estimate the battery capacity change during each interval [6]. Sizing of BESS is done for desired level of peak reduction using the load following method from a real load demand data [7].

The lead-acid, sodium-sulphor, and flow batteries with appropriate sizes are the good choice for bridging power and energy management at distribution level [8]. A methodology, to determine the size of lowest-cost zinc-bromine flow battery-based energy storage system, is developed and impact of control strategy on sizing is quantified for assessment [9]. Selecting suitable size of battery helps in shaving the peak demand, storing the excess energy and releasing the energy, whenever required, with minimum cost [10]. Authors of the paper [11] worked to find a unique critical value of the battery size such that total cost remains the same whether the battery size is larger than or equal to this value. The tool for finding optimal size of hybrid energy storage systems (HESS) incorporating batteries and ultra-capacitors for regenerative braking in electric railway systems has been proposed in [12].

The input and output rated power values of energy storage system (ESS) directly depend on charging and discharging features such as current and rate of charging/discharging and operational voltage. The variations in these parameters are kept within the limits so that there is no violation in the condition of maximum depth of discharge (DOD) [8]. The DOD plays major role in deciding the size of battery as upper limit of state of charge (SOC) is just a technical limit while the lower limit of SOC is directly related to maximum allowed DOD [12]. The energy storage, used with other energy resources, the capacity required to fulfillment of local electricity consumption is based on the average hourly load of the electrical network, desired typical hours of energy autonomy, and maximum depth of discharge and energy 
transformation efficiency of energy storage system [8]. Once the peak load shaving is established, the minimum size of BESS is obtained by finding maximum of the minimum energy supplied by the BESS and the minimum energy charged to the BESS [10].

To the best of authors' knowledge, no work is available which implements the concepts of LOF in practical load history data to obtain the critical load profile, which is assumed an outlier, for the size of battery. In this paper, an approach is proposed to establish the critical load profile for base year and year of interest which aims to find possible loading conditions during the season of peak demands. The critical load profile, which is an outlier, consists of the broadest peak in whole historical load pattern data. $k$-means clustering technique is implemented to isolate different groups of large and least varying electricity consumption days. The cluster of large variation consists of broadest peak demand profile and it is identified using concept of LOF. Though, the proposed approach is conservative but it is robust as well. The effectiveness of the proposed work is tested on a practical distribution system.

\section{BATTERY : AN OVERVIEW}

\section{A. Dynamics of battery}

During charging/discharging operations, battery follows following dynamic equation [11].

$$
\frac{d E_{b a t}(t)}{d t}=P_{b a t}(t)
$$

where $E_{\text {bat }}(t)$ is stored energy (Wh) in battery and $P_{b a t}(t)$ (W) is charging/discharging rate at time $t . \Delta E_{\text {bat }}(t)$ is the change in energy stored, as shown below.

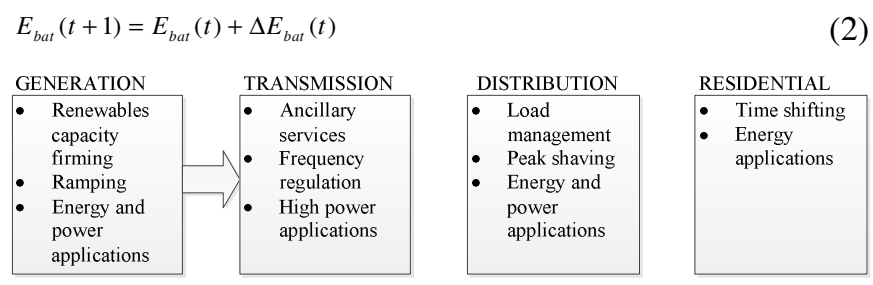

Figure 1. Energy storage value chain

\section{B. Applications}

The storages of energy find various applications in delivery of electrical energy from generation to end users and these can be deployed at any of subsystems of the power system. A value chain diagram, as shown in Fig. 1, depicts where and what are the applications in power system. At distribution level, the BESS is used in load leveling and peak shaving applications. With advancement in technologies and reduction in cost of installation, and operational and maintenance, the battery energy storage systems are emerging as powerful tool in, day-by-day, balancing of demand and supply at substation and end users level.

\section{Size}

Storage size requirement is expressed in pair of power and energy capacities that are decided in order to balance power flow during each interval, considering projected overload [3]. Power balance requirement is fluctuating power injections (increments) into and absorptions (decrement) from bulk power system [4]. The main points, which are to be considered in deciding the size of energy storage, are the operational constraints in the system. Size of the battery is fully utilized if it is designed based on $100 \%$ of DOD of battery. In such a case, battery will be cycled from state of full charge to full discharge [5].

\section{K-MEANS CLUSTERING ALGORITHM}

$k$-means is one of the simplest clustering algorithms which separate a given data set into a certain assumed number of clusters. The different groups are obtained based on attributes/features by an objective function such as sum of squares of distances between data and corresponding cluster centroid. Data objects in $n$ numbers are separated into $k$ groups by minimizing the objective function, as given below, with Euclidean distance as similarity feature [14].

$J=\sum_{j=1}^{k} \sum_{i=1}^{n}\left\|x_{i}^{(j)}-c_{j}\right\|^{2}$

The $k$-means clustering algorithm can be summarized in following steps:

1. Choose $k$ initial centers $\left(c_{1}, c_{2}, \ldots \ldots \ldots \ldots, c_{k}\right)$.

2. Assign each data object $x_{i}^{(j)}$ to its nearest cluster center $c_{j}$.

3. Obtain mean of all $x_{i}^{(j)}$ to update each cluster center $c_{j}$.

4. Repeat steps 2 and 3 till no further change is found in cluster centers i.e. they are converged to a set of values.

\section{LOCAL OUTLIER FACTOR}

The LOF [13] has a local approach and does comparison of density of each data object with that of objects in its neighborhood, and hence, it is based on relative densities of the neighboring data objects. The LOF comes from the field of knowledge discovery in databases (KDD) which assigns a degree of 'outlierness' to each object in the database, termed as LOF. An object having higher value of the LOF means that there is difference between the density around this object and its $k \mathrm{NN}$ ( $k$-nearest neighbors) and these objects are termed as outliers. Others, which are having the LOF approximately equal to one, exist within region of homogeneous density. With following steps, the LOF of each object can be computed.

1. First $k$-distance, the distance from an object to its $k^{\text {th }}$ nearest neighbor, is computed and then $k \mathrm{NN}$ objects which are within $k$-distance sphere are identified.

2. Reachability distance of an object $p$ with respect to $o$, an object under consideration, is computed as reach$\operatorname{dist}(p, o)=\max \{k$-distance $(o), d(p, o)\}$, where $d(p, o)$ is the distance between objects $p$ and $o$.

3. Local reachability density, $\operatorname{lrd}(o)$, defined as inverse of average of reachability distance of $k$-nearest neighbors of an object under consideration $o$, is computed as

$$
\operatorname{lrd}_{k}(o)=\frac{\left|N_{k}(o)\right|}{\sum_{p \in N_{k}(o)} \text { reach }-\operatorname{dist}_{k}(p, o)}
$$

4. $\operatorname{LOF}(o)$, of an object $o$ is computed as average of the ratios of local reachability density of objects in $k$ nearest neighbors of object $o$ to local reachability density of object $o$ itself as 


$$
\operatorname{LOF}_{k}(o)=\frac{\sum_{p=N_{k}(o)} \frac{\operatorname{lr} d_{k}(p)}{\mid N_{k}(o)}}{\left|N_{k}(o)\right|}
$$

The objects having LOF close to 1 are identified as part of cluster and the LOF for outliers are computed greater than 1. Outliers in each cluster are isolated with respect to a threshold assumed on LOF heuristically, and clusters are filtered into homogeneous objects.

\section{PROPOSED APPROACH to ESTABlish CRITICAL LOAD PROFILE}

There is different usage of electricity on different days in a year depending on several factors such as weather conditions, types of customers, days of week, times of year, etc. Thus, energy and power requirements are different on different days. Load profile information provides valuable analysis for implementation of storage for end user applications and is very useful tool in sizing of storage and designing appropriate control schemes.

Storage discharge duration is a key parameter in determination of its size, used for customer level applications and it is defined as amount of time that storage must be able to discharge energy, at the design power rating, without recharging. Discharge duration is estimated based, almost entirely, on load pattern having peak demand at each node in the distribution system. Therefore, a critical load profile is to be established for estimation of design discharge duration. Critical load profile can be obtained from historical hourly electricity consumption on a day or days when broad peak demand occurs. Estimating design discharge duration from critical load profile is a methodology, which is conservative and robust, with assumption that there is not unusual change in electricity consumption behavior [3].

The proposed approach implements k-means algorithm for clustering purpose and local outlier factor helps in identification of abnormal consumption, as per their degree of anomalies, which include load patterns with broadest peaks. Centroid load profile of a cluster is obtained by taking mean of the electricity consumptions in all load profiles of that cluster at different time intervals. In one cluster, out of all optimal number of clusters, there is a large variation in electricity consumption. This group, $C_{\text {peak }}$, consists of load profiles of peak load and can be identified as

$C_{\text {peak }}=\left\{C_{j} \mid \max _{j=1: n_{c}, i=1: T}\left(d C E N_{j}^{i}\right), \forall C_{j} \in \Omega\right\}$

Critical load profile, $C L P^{b}$, is having maximum discharge duration and hence, it is an outlier in $C_{\text {peak }}$.

$$
C L P^{b}=\left\{L P \in C_{\text {peak }} \mid \max _{l=1: x_{l}}\left(N_{\text {dsch }}(L P)\right) \& \operatorname{LOF}(L P)>1\right\}
$$

$E_{\text {tot }}^{L P}$, for any load profile $L P$, is determined by the area between the critical load profile curve and line for reference upstream grid demand $P_{\text {grid }}^{\text {ref }}$ as

$$
E_{\text {tot }}^{L P}=\int_{0}^{T}\left(P_{L P}-P_{g r i d}^{r e f}\right) d t, \quad P_{L P}>P_{g r i d}^{\text {ref }}
$$

Rated value of energy capacity $E_{\text {rated }}$ is decided while taking in account a minimum value of energy in battery.

$E_{\text {rated }}=\frac{E_{\text {tot }}^{C L P}}{\eta_{\text {dsch }}}+S O C_{\min } E_{\text {tot }}^{C L P}$

For the base year and assumed year $r$ from base year, the rated power of battery energy storage, $P_{\text {rated }}$, is set equal to $P_{\max }^{C L P^{b}}$ and $P_{\max }^{C L P^{r}}$, respectively.

Load growth, $L_{g r}^{r}$ in year $r$ is estimated as

$L_{g r}^{r}=r\left(L_{B L}+L_{S G}\right)$

where $L_{B L}$ is block loads added, due to housing developments, commercial buildings, industrial or agricultural operations etc., to the base year peak load in year of interest. $L_{S G}$ is standard or core load growth, happens due to regular increase in population and their financial capacities instead of block load additions, in load of base year.

Load growth information is very useful in determining projected load in coming years for deciding energy storage ratings. Heuristically, load growth is decided in percentage of base year peak load [3]. Critical load profile in year of interest $r$ is estimated as

$C L P^{r}=C L P^{b}+L_{g r}^{r}$

The peak hours on days just before and after day of critical load profile are lesser than that on day of this load profile. Thus, there is high possibility that the BESS is fully charged on day before, and, on day after, it will have enough charging intervals after discharging fully on day of critical load profile. Steps to determine nominal values of battery energy system are given below.

1) Determine optimal no. of clusters $\left(c_{1}, c_{2}, \ldots \ldots, c_{n_{c}}\right)$

2) Identify $c_{\text {peak }}$

3) Find critical load profile for base year $C L P^{b}$

4) Obtain load growth $L_{g r}^{r}$ in year $r$ from base year

5) Modify critical load profile for year $r$ as $C L P^{r}$

6) Set $P_{\text {grid }}^{r e f}$, reference demand at upstream grid

7) Estimate $E_{\text {rated }}, P_{\text {rated }}$

\section{TEST RESUlTS AND Discussions}

The effectiveness of the proposed approach is tested on Indian Institute of Technology Kanpur (IITK) distribution system getting power supply from Panki power grid via 33 $\mathrm{kV}$ lines. One $10 \mathrm{MVA}$ and $2 \times 5$ MVA, $33 \mathrm{kV} / 11 \mathrm{kV}$ transformers are installed in main substation. The 10 MVA transformer (Transformer 3) of main substation caters the major demand in IITK. Hourly load data of year 2013 of 10 MVA, $33 / 11 \mathrm{kV}$ transformer is considered for finding the feasibility of BESS installation. With optimal usage of batteries, it is possible to avoid overloading and minimize losses in the system. With battery energy storage, it is possible to set the reference power profile of upstream grid, using historical data of demand, while not violating the constraints of the BESS. 

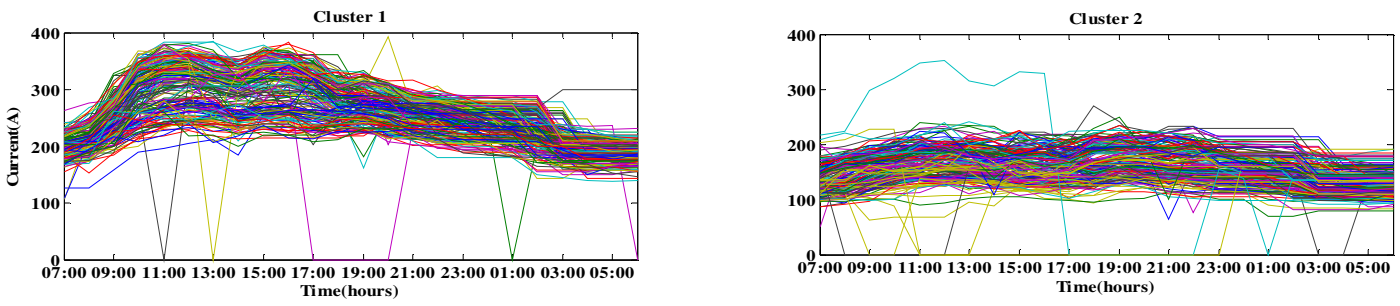

Figure 2. Clustering results of electricity consumption (in Amps) on Transformer-3
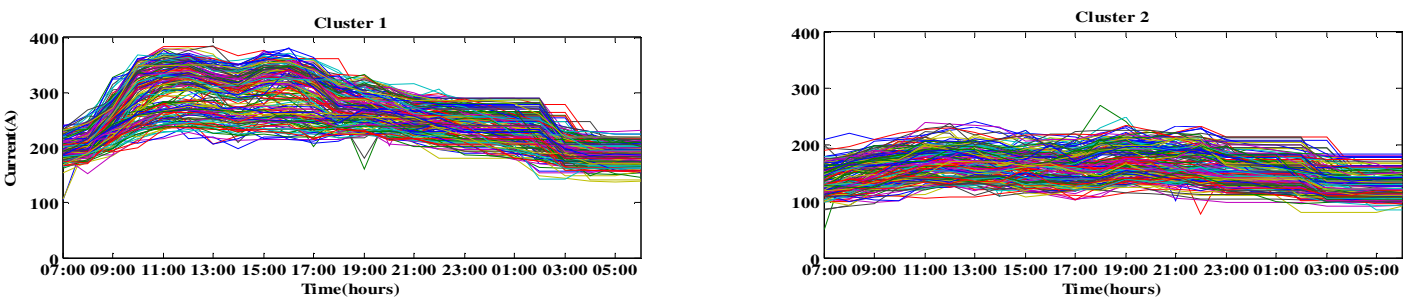

Figure 3. Clustering results of electricity consumption (in Amps) on Tr-3 without outliers
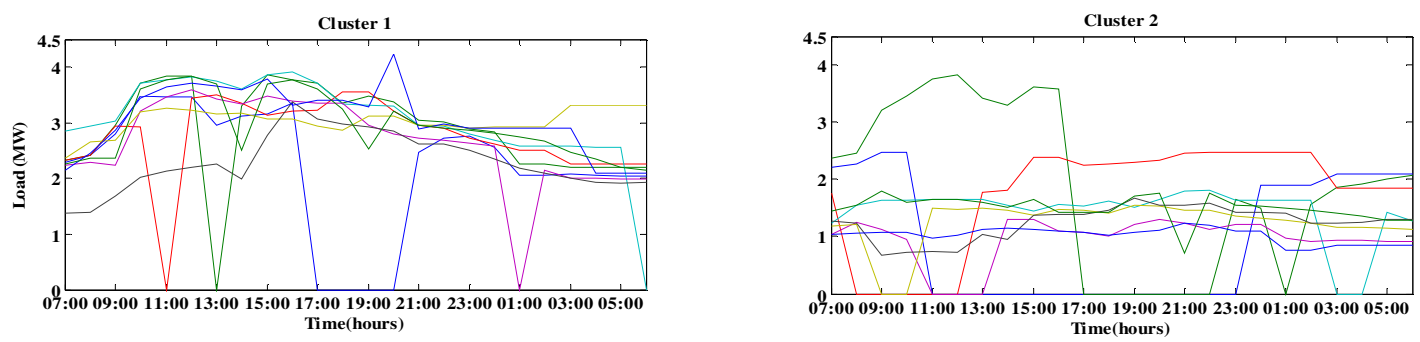

Figure 4. Abnormal consumptions as MW loading in different clusters

\section{A. Implementation of Clustering Algorithm}

The $k$-means clustering algorithm is applied on hourly loading of feeder of Transformer 3. Optimal number of clusters is found while validating with Silhouette coefficient. For 2 numbers of clusters, Silhouette coefficient is obtained as 0.7865 which is maximum among that of different number of groups of load profiles. Centroid load profile is calculated for both clusters and group of maximum demands, $C_{\text {peak }}$ is identified. In IITK system, the peak electrical load demand occurs between 09:00 and 17:00 as shown in Fig. 2 and, during this period, major electricity consumption is in academic area.

In cluster 2, except outliers, the electricity consumption by the end user is having less variation, and no peak and valley are identified and can be seen from Figs 2 and 3. So, during these days power distribution system is not overloaded and losses would not be higher. In days of cluster 1, variation in electricity consumption is found with peak demands during 09:00 to 17:00 hrs. So, the whole distribution system associated with transformer 1 is overloaded. More shutdowns are needed for preventive and maintenance work. Although maximum electricity consumption is demanded on a few days in a year but on these days, the reliability of the system is jeopardized.

\section{B. Finding Local Outlier in different Clusters}

In different clusters, LOF is obtained for each load pattern to distinguish outliers from other homogeneous load patterns. In this paper, heuristically, thresholds are set for LOF as 1.5 in cluster 1 and 1.7 in cluster 2, to show 9 outliers as given in Table I. These outliers occur, mainly, due to shutdowns taken for maintenance purpose and regular/irregular broad peak demand. These irregular consumptions are ranked according to their outlying nature. The abnormal consumptions of both the clusters are shown in Fig. 4.

TABLE I. DAYS WITH LOF IN DESCENDING ORDER FROM HIGHEST

\begin{tabular}{|c|l|c|c|c|c|c|c|c|c|c|}
\hline Cluster & day & 241 & 249 & 250 & 218 & 172 & 198 & 119 & 172 & 224 \\
\cline { 2 - 10 } 01 & LOF & 5.19 & 3.85 & 3.48 & 2.73 & 2.50 & 2.26 & 2.17 & 1.67 & 1.54 \\
\hline $\begin{array}{c}\text { Cluster } \\
02\end{array}$ & day & 272 & 225 & 125 & 35 & 83 & 97 & 76 & 86 & 15 \\
\cline { 2 - 10 } & LOF & 7.23 & 6.73 & 5.01 & 3.01 & 2.88 & 2.29 & 2.23 & 1.82 & 1.74 \\
\hline
\end{tabular}

\section{Finding Critical Load Profile}

In different clusters, with proposed approach, the critical profile is obtained for estimation of size of battery energy storage. In cluster 2 , the electricity consumption is flat i.e. no major peak and valley occurs, Fig. 2 and 3. $C L P^{b}$, found in $C_{\text {peak }}$, is July 17 and Aug 06, 2013 as on both days, the $N_{d s c h}$ is same and equal to 11 as shown in Table II. In this paper, base year is 2013, and $r=5$ (i.e. year of interest from base year) is considered. Block load additions $L_{B L}$ and standard load growth $L_{S G}$ are assumed zero and $2 \%$ of base year peak load, respectively. $C L P^{r}$ is estimated to determine the size of battery energy storage system. The critical load profile considering 5 years load growth factor with $3.5 \mathrm{MW}$ reference system demands are shown in Fig 5. The power and energy rated values are decided based on this reference demand. 

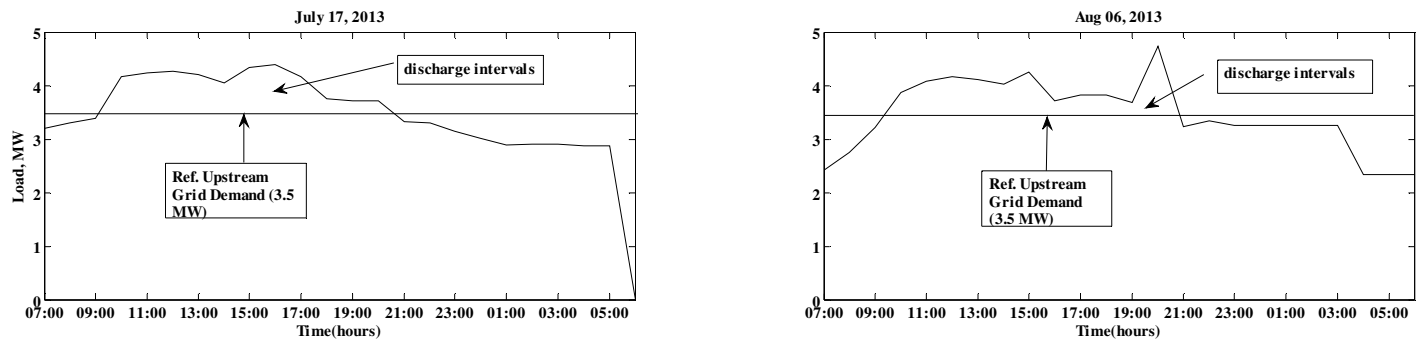

Figure 5. Critical load profiles with load growth for year 05

TABLE II. Power And ENERgy Demand in CRitical LoAd Profile (REFERENCE UPSTREAM GRID DEMAND=3.5 MW)

\begin{tabular}{|l|l|l|l|l|l|}
\hline $\begin{array}{l}\text { Day } \\
(2013)\end{array}$ & $P_{\max }$ & $E_{\text {tot }}$ & $N_{\text {dish }}$ & $\begin{array}{l}\delta_{\text {dsch }} \\
(100 \% \text { eff. })\end{array}$ & $\begin{array}{l}\delta_{\text {dsch }} \\
(70 \% \text { eff. })\end{array}$ \\
\hline July 17 & 1.238 & 5.746 & 11 & 4.64 & 6.63 \\
\hline Aug 06 & 0.894 & 6.455 & 11 & 7.22 & 10.32 \\
\hline
\end{tabular}

Number of discharge intervals on days of these two critical profiles is maximum Table II. There are enough intervals for charging on same and next consecutive days. Power rating and energy rating are based on two different technologies of storage systems. Maximum power demand and the energy demand as 1.238 MW and 6.455 MWh in two critical load profiles are used to design size of storage. So power rating of storage is sized as $1.25 \mathrm{MW}$ and energy rating is obtained using (9), considering $\eta_{d s c h}=0.8$ and $S O C_{\min }=0.2$ depending on different discharging capability as shown in Table III.

TABLE III. ENERGY RATING BASED ON DISCHARGING CAPABILITY (2\% ANNUAL GROWTH, UPSTREAM GRID DEMAND=3.5 MW)

\begin{tabular}{|l|l|l|l|l|l|}
\hline Discharging Capability (min) & 60 & 30 & 15 & 05 & 01 \\
\hline Energy rating (MWh) & 8.88 & 4.44 & 2.22 & 0.74 & 0.15 \\
\hline
\end{tabular}

\section{CONCLUDING REMARKS}

A method is developed to find critical load profile to size the battery storage system. The $k$-means clustering algorithm is implemented to separate the similar load profiles in historical yearly electrical consumption data of practical system. Cluster of load profiles, consisting peak demand, is obtained and broadest peak load profile, considering it as an outlier, is identified using concept of local outlier factor. The yearly load growth is considered in sizing the BESS so that it should be capable to be used in peak shaving and load leveling applications in assumed year from base year. The proposed algorithm suggests the power rating of BESS and energy rating is calculated for different rate of required discharge capabilties. The battery storage system with power rating $1.25 \mathrm{MW}$ and energy rating $8.9 \mathrm{MWh}$ is able to maintain the demand not more than 3.5 MW at transformer no. 3 of 33/11 kV substation at IIT Kanpur. The different energy rating can be decided depending on discharging capability as shown in Table III. The sized BESS will be capable to be used in peak shaving and load leveling applications till 2018.

\section{REFERENCES}

[1] http://energystorage.org

[2] http://IEEE.smart grid.org

[3] J. Eyer, J. Iannucci, and P. C. Butler, "Estimating electricity storage power rating and discharge duration for utility transactions and distribution deferral," Sandia Rep. SAND2005-7069, Nov. 2005.

[4] M. Kinter-Meyer, P. Balducci, W. Colella, M. Elizondo, C. Jin, T. Nguyen, V. Viswanathan and Y. Zhang, "National assessment of energy storage for grid balancing and arbitrage: phase 1, WECC, ERCOT, EIC, vol. 1: technical analysis" Pacific North West Laboratory and DOE, June 2012.

[5] M. Kinter-Meyer, P. Balducci, W. Colella, M. Elizondo, C. Jin, T. Nguyen, V. Viswanathan and Y. Zhang, "National assessment of energy storage for grid balancing and arbitrage: phase II, WECC," Pacific North West Laboratory and DOE, September 2013.

[6] I. Papič, "Simulation model for discharging a lead-acid battery energy storage system for load leveling," IEEE Trans. On Energy Conv., vol. 21, no. 2, pp. 608-615, June 2006.

[7] C. Venu, Y. Riffonneau, S. Bacha, and Y. Baghzouz, "Battery storage system sizing in distribution feeders with distributed photovoltaic systems", IEEE PowerTech Conf., Bucharest, Romania, July 2009.

[8] J. K. Kaldellis, D. Zafirakis, and E. Kondili, "Optimum sizing of photovoltaic-energy storage systems for autonomous small islands", Int. J. of Electrical Power and Energy Systems, vol. 32, no. 1, pp. 2436, Jan. 2010.

[9] T. K. A. Brekken, A. Yokochi, A. von Jounne, Z. Z. Yen, H. M. Hapke, and D. A. Halamay, "Optimal energy storage sizing and control for wind power applications," IEEE Trans. On Sust. Energy, vol. 2, no. 1, pp. 69-77, Jan 2011.

[10] S. X. Chen, H. B. Gooi, and M. Q. Wang, "Sizing of energy storage for microgrids," IEEE Trans. On Smart Grid, vol. 3, no. 1, pp. 142- 151, March 2012.

[11] Y. Ru, J. Kleissl, and S. Martinez, "Storage size determination for gridconnected photovoltaic systems," IEEE Trans. On Sust. Energy, vol. 4, no. 1, pp. 68-81, Jan. 2013.

[12] S. de la Torre, A. J. S.-Racero, J. A. Aguado, M. Reyes and O. Martinez, "Optimal sizing of energy storage for regenerative braking in electric railway systems," IEEE Trans. On Power Syst., vol. PP, no. 99, pp. 1-9, Aug 2014.

[13] M. M. Breunig, H. P. Kriegel, R. T. Ng, and J. Sander, "LOF: Identifying density-based local outliers," ACM SIGMOD Record, vol. 29, no. 2, pp. 93-104, June 2000.

[14] A. Jain, M. Murty, and P. Flynn, "Data clustering: A review," ACM Comput. Surv., vol. 31, no. 3, pp. 264-323, 1999. 